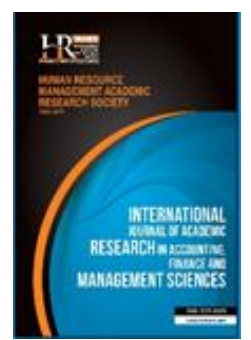

International Journal of Academic Research in Accounting, Finance and Management Sciences

Vol. 10, No.2, April 2020, pp. 211-222

E-ISSN: 2225-8329, P-ISSN: 2308-0337

(C) 2020 HRMARS

www.hrmars.com

To cite this article: Shari, A., Mahat, F. (2020). The Relationship of Equity Sector Returns and Composite Index in Malaysia, International Journal of Academic Research in Accounting, Finance and Management Sciences 10 (2):211-222.

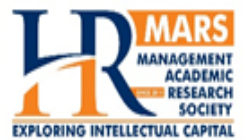

www.hrmars.com

ISSN: $2225-8329$

\title{
The Relationship of Equity Sector Returns and Composite Index in Malaysia
}

\begin{abstract}
Aminah Shari ${ }^{1}$ Fauziah Mahat ${ }^{2}$
${ }^{1}$ Department of Accounting and Finance, Faculty of Economics and Management, Universiti Putra Malaysia, 43400 UPM, Serdang, Selangor, Malaysia, ${ }^{1}$ E-mail: aminah83@ums.edu.my (Corresponding author)

Abstract

This paper examines the relationship between sectoral equity index returns with the composite index in the Malaysian stock market over the period of 1999 to 2019. The wavelet method has been used to decompose equity returns into different time series frequencies and Multivariate-GARCH Dynamic Conditional Correlation (DCC) to examine the volatilities and correlations of equity indexes. The wavelet coherence analysis indicates a higher co-movement between returns on sectoral equity index with returns on the Malaysian stock index during sample period. The results suggest that the return of the equity sector leads stock market returns except for industrial, plantation, tin mining and trade and services. There is also overall increase of short, medium and long-run co-movement between equity sector and market returns. Moreover, the plantation, properties and tin and mining sector have negative unconditional correlation with the stock market, which is a good sign of diversification benefits. The findings highlight the importance of taking into consideration the time and frequency-varying properties as investors can minimize risk through diversification.

Key words

Co-movement, Wavelet Analysis, Continuous Wavelet Transform, Multivariate-Garch, Volatility

Received: 05 Jun $2020 \quad$ C The Authors 2020

Revised: 19 Jul $2020 \quad$ Published by Human Resource Management Academic Research Society (www.hrmars.com)

Accepted: $\quad 28 \mathrm{Jul} 2020 \quad$ This article is published under the Creative Commons Attribution (CC BY 4.0) license. Anyone may Published Online: 04 Aug 2020 reproduce, distribute, translate and create derivative works of this article (for both commercial and non-commercial purposes), subject to full attribution to the original publication and authors. The full terms of this license may be seen at: http://creativecommons.org/licences/by/4.0/legalcode
\end{abstract}

\section{Introduction}

The interdependence and contagion of financial markets are widely researched topic in empirical finance (Shahzad et al., 2017). The interdependence of financial markets measures financial integration and globalization of economy. For instance, for the last decades, many developing countries have removed gradually financial and economic barriers which led to greater financial integration (Hillier \& Loncan, 2019). The comovement among the global equity markets has recently attracted international investors and understanding of their economic features plays an important role in the empirical finance, namely asset pricing, risk management, and hedging. More specifically, returns of market indices, sectoral indices and individual indices have become relatively important (Balli \& Balli, 2011). For example, when the international stock markets exhibit weak comovement, it implies that there are high diversification benefits and risk sharing. In contrast, strong comovements suggest that there is limited opportunity for portfolio diversification which increases the portfolio risk (Balli \& Balli, 2011). Additionally, the evidence shows contagion which influences the financial markets. Indeed, the contagion effect refers to sudden increase in short-term comovement. It involves in events about finance and real economy can spread over the different markets which then consequences real economy (Chen et al., 2017). Therefore, understanding comovement of sector level stock returns is essential for equity markets. It enables investors, both local 
and foreign, to access investment opportunities in global equity markets to pool their risks, generating high returns and reducing risks. It limits fluctuations in domestic economic development. Put it differently, it is essential for global diversification, allocation of assets and risk management (Kim \& Sun, 2017).

Previous studies that have been investigated the equity markets at country level are vast; however, research on sector level of developing economies has not received adequate research attention. Therefore, we attempt to analyze the dynamic interdependence among sectoral stock indices using time-frequency analysis. We focus on sector-level stock indices of developing countries, especially Malaysia. Sector analysis can provide clear understanding regarding heterogeneity and sensitivity of particular stock to other. Malaysian stock market is one of pioneer which investors can invest (Liew et al., 2018). Despite the economic importance of developing countries, international investors devote attention to developing countries, seeking high returns and stability and these markets usually offer diversification opportunity (Zaremba \& Maydybura, 2019). Notably, the research on sector based returns possesses advantages over the stock markets at country level (Chen et al., 2017; Kim \& Sun, 2017). These include: higher diversification benefits, higher performances and display of heterogeneity among sectoral stock indices.

The paper uses wavelet analysis and MGARCH-DCC approach to extend the existing literature on interdependence and contagion of sector stock returns in Malaysia. This wavelet method is suitable as it allows better understanding of comovement among financial markets (Albulescu et al., 2015; Shahzad et al., 2017). It is a unique time-varying framework that can analyze the interdependence of sector-based stock returns at multiple time and frequency domains. The approach is multiresolution decomposition as it decomposes time series into time-frequency space. Additionally, it not only captures time-varying information of interdependence of sector stock returns but also provides different time-scales, which enables the researchers to identify the specific scales that contribute most to variability and variations of domains over time (Torrence \& Compo, 1998). To put it differently, wavelet analysis provides useful insight on empirical problem, enabling one to identify the interdependence and contagion by using time-frequency space analysis (Yang et al., 2016).

We use wavelet analysis, novel methodology, to examine the interdependence among sector indices using returns of sector stocks. The new approach outperforms the standard time series techniques, namely regression, Autoregressive Distributed Lad model (ARDL), Co-integration and Error Correction Model, Granger causality and Vector Autoregression (VAR). First, a drawback of applying standard models is that they require the time series to be stationary. In this regard, we may lose useful insight regarding real features governing returns of sector indices. Any techniques that require transformation of data can provide biased estimates, leading to wrong interpretations. Based on biased and conflicting results, it cannot be drawn from policy implications. Second disadvantage of these methods is that they allow only two scales (short-run and long-run effects).

Wavelet analysis overcomes the mentioned limitations. The approach is more flexible as it accommodates both stationary and non-stationary time series. It does not require data transformation, protecting completely the loss of useful information that the time series data contains. The ability of wavelet analysis is that it can be applied without imposing restrictions to signal (Sharif et al., 2017).

\section{Literature review}

Co-movement of financial assets has been investigated in numerous influential studies. The aim is to understand the interdependence of two or more financial markets or assets; however, the recent studies on co-movement analysis have concentrated on aggregate level without focusing on sector level analysis. Specifically, studies with methodologies similar to this study except in Benlagha (2014) for French bond portfolio only and Erdogan et al. (2013) for stock and maritime sector index; the latter studies of Chen et al. (2017) for healthcare sector index and US, UK and Germany stock market, el Alaoui et al., (2014) for Dubai financial stock market index and Aloui, Hammoudeh, and Hamida (2015) for Islamic Stock and Sukuk have all remarked that the markets in question experiences a process of co-movement in varying degrees. An associated finding is that the benefits of portfolio diversification vary across frequencies and time. The empirical studies have stated that the high level of co-movement related to a lower degree of diversification benefits. Therefore, the strong correlation between the sectors under investigation indicated lower diversification benefits. 
Several studies demonstrate to the limited diversification benefits of stock market. Marfatia (2017), Mensi et al. (2017), Mimouni et al., (2016) investigate the different geographical region correlation. Researchers have mentioned significant co-movement between developed markets and emerging markets (Buchanan et al., 2011; Marfatia, 2017), developed and BRICS stock market (Mimouni et al., 2016; Mohamed Dahir et al., 2018) and Gulf Cooperation Council countries (Mensi et al., 2017). However, the measure do not capture the level of portfolio diversification implication as they measure inter market (Mensi et al., 2017; Buchanan et al., 2011). Therefore, as highlighted in Buchanan et al. (2011), it is possible to investigate effective of diversification in capital market investment on different type of asset class, and improve the investor's portfolio decision (Mensi et al., 2017). This shows, there is a need to analyze the comovement of stock return and volatility at the sectoral level which is relatively less explored in the literature.

Relatively few studies have examined co-movements using sectoral returns, and most of these employed individual sector analysis. Chen et al. (2017) examined health care sector index; Ben-Salha et al., (2018) and Vacha \& Barunik (2012) US energy sector; Reboredo \& Uddin (2016) metal sector; Hiang Liow (2012) and Liow and Angela (2017) real estate sector, Mensah and Premaratne (2017) banking sector and Pal \& Mitra (2019) automobile sector. In fact, this paper emphasizes that previous study on co-movement of specific sector suggesting conflicting findings. For example, Hargis \& Jianping (2006) show that a shift in factor importance from country to industry. Rehman \& Shah (2016) confirm the sector varying coefficients, indicating the sectoral riskiness varies, suggesting for future sectoral stock market investment portfolio (Poynter et al., 2013). The paper to apply wavelet analysis method in this context was Ben-Salha et al. (2018). They find significant co-movement of energy consumption with US industrial sector under high frequency band. Applying the same methodology, Chen et al. (2017), considering the cross-market correlation of the health care sector. They applied three different approaches of wavelet analysis and find that health care sector in US have a statistically significant only for long run. Therefore, the investors can follow the health care price pattern of US to predict future price of health care stock price.

Graham \& Nikkinen (2011) first proposed the use of wavelets to estimate the co-movement of international stock markets from European countries. They estimate the return of each stock annually for three-dimensional wavelet coherency approach using weekly returns for the period January 1999 to October 2009 for stock that was in the Morgan Stanley Capital International. They find that the comovement is stronger at higher frequencies. Kallberg \& Pasquariello (2008) examine the co-movement of US stock market indexes. Their data set consists of 82 industry indexes from January 1976 through December 2001. They also examine the co-movement among the indices at weekly level by using FGLS rolling regressions. However, they find contradict finding that co-movement of stock markets changes is not significantly in time. Among the studies that explore sector wise-stock return, Poynter et al. (2013) suggest that there are interrelationship between different sector indices in US. Recent research that demonstrate the empirical support that investment horizon among investors matters in credit and stock markets is found in Shahzad et al. (2018) and Shahzad et al. (2017), in equity and bond market (Sakemoto, 2018). However, the literature reveals a deficiency. Wavelets estimates of return did not consider comprehensive sector level analysis. As evidence on previous finding limited to develop countries and individual sector level only.

In summary, this paper fills an important gap in the important of capturing differences in investor horizons. Thus, there is a need to be made between short-term long-term investors. The empirical results have practical implications for portfolio managers in asset allocation to different sectors and risk management. A wavelet approach for estimating market return has been utilised in this study. Wavelet analysis makes it possible to identify regions in a time-frequency space where two stock market are co-vary indicating the benefits of portfolio diversification are decrease.

\section{Methodology of research}

\subsection{Wavelet coherence}

To identify the dependence between two time series in the time and frequency domains, there are three approaches that can be applied. These include cross-wavelet power, wavelet power spectrum and cross- wavelet transform (Graham \& Nikkinen, 2011). The wavelet power spectrum (WPS) measures the 
variance of single wavelet that detects and measures the relations between two time series, the crosswavelet power assesses the covariance of the time series while the cross-wavelet transform can control the dependences of frequency and time between two time series. According Aguiar-conraria et al. (2008) defined wavelet coherence (WTC) as "the ratio of the cross-spectrum to the product of the spectrum of each series, and can be thought of as the local correlation (both in frequency and time), between two time series". The wavelet coherence is expressed in terms coefficient of correlation of time-frequency space. We define the wavelet coherence as follows:

$$
R_{n}^{2}(s)=\frac{\mid S\left(\left.s^{-1} W_{n}^{X Y}(s)\right|^{2}\right.}{S\left(s^{-1}\left|W_{n}^{X}(s)\right| \bullet S\left(s^{-1}\left|W_{n}^{Y}(s)\right|^{2}\right)\right.}
$$

Where $\mathrm{R}^{2}$ represents for wavelet coherency and $\mathrm{S}$ is for a smoothing operator. Interestingly, the value of wavelet coherence ranges from 0 to 1 . It is a localized correlation coefficient in time-frequency space and also is useful technique for analysis of co-movements across two time series. The wavelet coherency can be interpreted similarly to the correlation coefficient suggesting strong dependence when the value is close to 1 and weak dependence when the value is close to 0 . Likewise, the wavelet power spectrum explains the variance of a time series and covariance which capture cross wavelet power between two-time series at each scale or frequency. If the variance of a time series becomes large, the wavelet suggests that the existence of sizeable power spectrum. The statistical significance of wavelet coherence coefficient is estimated using Monte Carlo simulation, though little is known its theoretical contribution (Torrence \& Compo, 1998).

\subsection{MGARCH-DCC}

The empirical analysis started with the investigation of the co-movement patterns between equity sectors and composite index and their changes over time. GARCH analysis can be used to detect stylized facts of financial time series namely volatility clustering and fat tails. It has been applied to volatility modelling. In addition, the Multivariate Generalized Autoregressive Conditional Heteroskedasticity (MGARCH) model is widely used for portfolio optimization, pricing of assets and derivatives, computation of the value at risk $(\mathrm{VaR})$, futures hedging, volatility transmitting and asset allocation (Minovi \& Simeunovi, 2002). Engle (2002) develops the dynamic conditional correlation (DCC)-GARCH model, which offers flexibility to simultaneously model the multivariate conditional volatility of stock returns and their timevarying correlations. The DCC is a multivariate $\mathrm{GARCH}$ model in which correlation are time-varying according to autoregressive specification. Engle (2002) develop two-step namely estimation of univariate GARCH model for each series and dynamic conditional correlations from standardized residuals.

$$
H_{t}=D_{t} R_{t} D_{t}
$$

In equation $2, H_{t}$ is the $\mathrm{n} \times \mathrm{n}$ conditional covariance matrix, $R_{t}$ is the dynamic correlation matrix and $D_{t}$ is a diagonal matrix with time- varying standard deviations.

$$
\begin{aligned}
& D_{t}=\operatorname{diag}(\mathrm{h} 111 / 2, \ldots \mathrm{hkkt} 1 / 2) \\
& \mathrm{Rt}=\operatorname{diag}(\mathrm{q} 11 \mathrm{t}-1 / 2 \ldots \ldots . \mathrm{qkkt}-1 / 2) \mathrm{Qt} \operatorname{diag}(\mathrm{q} 11 \mathrm{t}-1 / 2 \ldots \ldots . \mathrm{qkkt}-1 / 2) \\
& \text { Where } Q_{t} \text { is a symmetric positive definite matrix: } \\
& Q_{t}=\left(1-\theta_{1}-\theta_{2}\right) \bar{Q}+\theta_{1} \varepsilon_{t-1} \varepsilon_{t-1}+\theta_{2} \theta_{t-1}
\end{aligned}
$$

$\bar{Q}_{\text {is }}$ the $\mathrm{n} \times \mathrm{n}$ unconditional correlation matrix of the standardized residuals $\varepsilon_{i t}$. The parameters $\theta_{1}$ and $\theta_{2}$ are non-negative with a sum of less than unity. The study calculates the conditional correlation at time tas:

$$
\rho_{i j, t}=\frac{q_{i j, t}}{\sqrt{q_{i i, t} q_{j j, t}}}, \forall \mathrm{i}, \mathrm{j}=1, \ldots \ldots \ldots, \mathrm{n}, \mathrm{i} \neq \mathrm{j}
$$

The Quasi-Maximum Likelihood Estimation (QMLE) is used to estimate the model. This rich conditional correlation parameterization allows examining the co-movement of one market with each 
other market and inferring how the dependence evolves over time. As a result, the least correlated stock indices would offer better diversification benefit to investors.

\subsection{Data and Descriptive Statistics}

The data used in this study consists of sectoral equity indices and stock market indexes. The paper uses daily data that ranges from 5 February 1999 to 6 February 2019 extracted from Thomson Reuters DataStream. The sector breakdown is according to the Securities Commission of Malaysia classification. Thus, the overall sector for stock market consists of fourteen sectors namely construction, consumer product and services, energy, financial services, health care, industrial products and services, plantation, property, real estate investment trust (REITS), SPAC, technology, telecommunication and media, transportation and logistics and utilities. The sample sectors consist of consumer product (LCONP), construction (LCONS), finance (LFIN), industrial (LIND), industrial product (LINDP), plantations (LPLNT), properties (LPRO), tin and mining (LTNM) and trade and services (LTNS). In addition, the used of sector portfolios would minimize the impact of any survivorship bias or look-ahead bias. In addition, sector portfolios are useful in this context because of the wide variability in business cycles and risk properties across the firms over these sectors (Faff et al., 2000). The study used the daily frequency data due to following reasons, first, more complete information on the dynamic conditional correlation than the monthly data. More specifically, using the daily frequency data is more useful for investors to build an optimal portfolio and generate economic gains. On the other hand, Mensi, Hammoudeh, and Kang (2017) document that a daily data model is a better predictor of returns than a monthly data model. The equity sector return was computed as the first difference of the logarithm of daily indexes times 100 . In other words, the formula for equity sector returns can be written as follows:

$$
\mathrm{Rt}=100 \times \log (\mathrm{Pt} / \mathrm{Pt}-1)
$$

Where Rt indicates the stock returns and P represents stock index levels at the time $(t)$ and $(t-1)$.

Table 1. Descriptive Statistics of Sectoral Indices

\begin{tabular}{|c|c|c|c|c|c|c|}
\hline & Mean & Std. Dev. & Skewness & Kurtosis & Jarque-Bera & Observations \\
\hline KLCl & 0.007 & 0.353 & -0.659 & 14.277 & $27356.990^{* * *}$ & 5093.000 \\
\hline LCONP & 0.012 & 0.283 & -0.583 & 12.959 & $21334.080^{* * *}$ & 5093.000 \\
\hline LCONS & -0.003 & 0.563 & -1.093 & 19.397 & $58071.370^{* * *}$ & 5093.000 \\
\hline LFIN & 0.009 & 0.409 & -0.390 & 13.465 & $23369.250^{* * *}$ & 5093.000 \\
\hline LIND & 0.008 & 0.349 & -0.422 & 14.750 & $29450.150^{* * *}$ & 5093.000 \\
\hline LINDP & 0.006 & 0.377 & -0.789 & 13.300 & $23043.220^{* * *}$ & 5093.000 \\
\hline LPLNT & 0.013 & 0.426 & -0.357 & 18.804 & $53108.020^{* * *}$ & 5093.000 \\
\hline LPRO & -0.001 & 0.467 & -0.566 & 14.835 & $29996.540^{* * *}$ & 5093.000 \\
\hline LTNM & 0.010 & 1.136 & 2.057 & 67.571 & $888369.200^{* * *}$ & 5093.000 \\
\hline LTNS & 0.005 & 0.382 & -0.518 & 14.660 & $29078.530^{* * *}$ & 5093.000 \\
\hline
\end{tabular}

Statistical significance at $* p<0.05, * * p<0.01$, and $* * * p<0.001$

Standard deviations (std. dev.)

Table 1 shows the descriptive statistics of returns for sectoral indices and market returns. With regard to sectoral indices, it appears that the volatility represented by the standard deviation is the highest for tin and mining sector and the lowest volatility for the consumer product. The average daily returns are relatively small than standard deviation, but the technology sector indicated the lowest average returns and highest volatility among the selected sectors. The skewness was negative for all selected sectors except in tin and mining sector. The finding in line with previous study of Mensah \& Premaratne (2017) which found the banking sector negatively skewed. As a result, based on Jarque-Bera statistic, the study rejected the null hypothesis demonstrating that the data were normally distributed in all series.

\subsection{Empirical Results and Discussions}

In this section, the paper implements the theoretical results on the wavelet coherence analysis. The paper use wavelet coherence to identify the co-movement and the lead-lag relationship between sectoral 
indices and market return. Accordingly, the lead-lag relationship is important in terms of identifying the cause-effect relationship between the selected indexes. The main reason for using wavelet coherence analysis is to address the time-varying property of co-movement in different holding periods (Chen et al., 2017). On the other hand, the benefit of the wavelet analysis is it can perform a multiresolution analysis. That is, it allows analyzing the data at different scales at the same time.

\subsection{The Results of the Wavelet Coherency Approach}

In this section, the paper presents the continuous wavelet analysis to investigate the co-movement and lead-lag relationship between sectoral indices and market return. Figure 1 shows the wavelet coherence analysis of sectoral indices and market returns. The vertical axis refers to the different holding periods represented from scale 1 (one day) up to scale 10 (1024 days). The horizontal axis refers to time element. The horizontal axis covers study periods from 2002 to 2019, corresponding to 1000 and 5000 (i.e., 2003, 2007, 2011, 2015 and 2019). Next, the study further divides these levels into three holding periods, namely 2- to 64-day scales indicating short term, 64- to 256-day scales indicating medium term, and 256- to 1024-day indicating long term dynamics. The figure uses a color code to measure the degree of correlation or co-movement between the pair of indexes. The red color indicated the warmer regions refer to the two series are highly correlated. Meanwhile the blue color indicated the cooler regions refer to that two series are low correlated. The 5 percent significant level was obtained from the Monte Carlo simulations is represented by the curved line.

Next, in order to investigate the lead-lag relationship of sectoral indices and market return, the wavelet coherence phase difference continues to reveal co-movement in index pairs through different investment horizons or holding period. Moreover, arrows representing phase differences indicate the direction of interdependence and cause-effect relationship. When the vector arrows pointing to the right, it was indicated that the indexes are in phase (positive correlation), however, when they pointing to the left, it shows that the indexes are out of phase (negative correlation). The results reveal that the majority of sectors strongly co-move. In addition, the impact changes across low-frequency scales. More specially, the sectors are positively associated with each other. For all indices, there are lead-lag relationships between the indices except for industrial, plantation, tin mining and trade and services. From figure 1, a phase difference of zero indicating that the sectoral indices and market return move jointly in the same direction, while an out of phase difference indicates that pair series move in opposite direction.

Based on figure 1, the co-movement between sectoral indices and market return are positive over time and frequency domains. However, the coherence in the index pair of sectoral indices and market return increases at low-frequency scale (64-256 days and 256-1024 days), and they ranging from about 2002 to 2019. Co-movement of sectoral indices and market return shows high coherence in construction, consumer product, finance, industrial, industrial product, plantation, properties and trade and services sectors except in tin and mining sector, the index pair is statistically significant. The correlation between trade and service sector indices and market return demonstrates a significant interdependence exists at all scales namely, the short, medium and long term over 2002 to 2109, however, the highest level of coherences (co-movement) was recorded at scales ranging from 64 to 1024 days scales from 2002 to 2015. In trade and service sector index, the arrows point rightward and downward, indicating that sector index and market return are positively correlated, and sector index lead market returns. According to figure 1 (c), (d) and (i), the plots pair of wavelet coherence shows the highest significant co-movement over time and frequency domains. The correlation between finance, industrial and trade and services are relatively stronger for all investment holding period namely short holding period, medium- and long-term holding period over 2003 to 2015. In the most three significant sectors, the arrows point rightward and downward, indicating that sector returns and market returns are positively correlated, and sector returns lead market returns. On average, the study noticed that figure 1 (a), (b) and (e) wavelet coherence reveal that sector returns and market returns show average significant co-movement over time and frequency domains in Malaysia. However, the coherence in the index pair increases at lower frequency (256-1024 days) during the period of 2003 to 2011 for construction, consumer product and industrial product. The arrows (lead-lag relationship) point rightward and downward at 64-256 days from 2003 to 2015 . Therefore, there is a positive relationship between the index pair, and sector returns lead market returns benchmark. 
However, the wavelet coherence of figure $1(\mathrm{f}),(\mathrm{g})$ and $(\mathrm{h})$, show the least association, indicating no co-movement. There is significant small blue region both the middle and low scales, but these show that wavelet coherence decreases gradually from higher to lower frequency bands. The lead-lag relationships seem to suggest negative associations and that market return lead sector returns. However, the comovement between sector return and market return are not statistically significant as shown in figure $1(\mathrm{~h})$, as the blue color dominates the area.

Figure 1. Wavelet coherence for equity sectoral indices and market returns

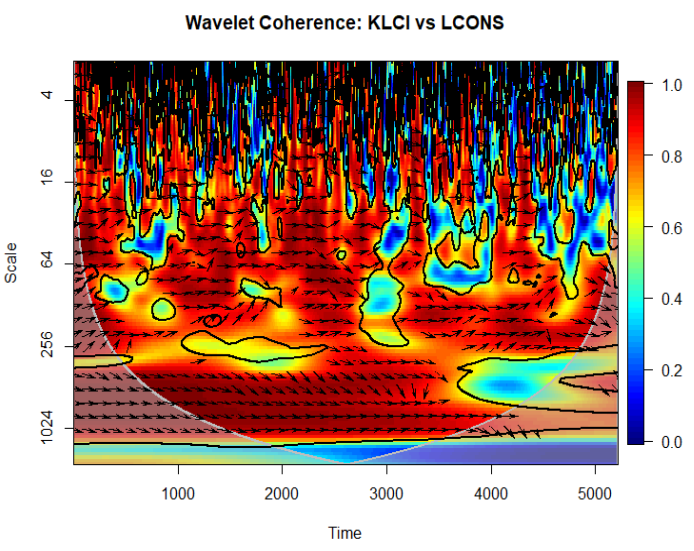

(a) Construction

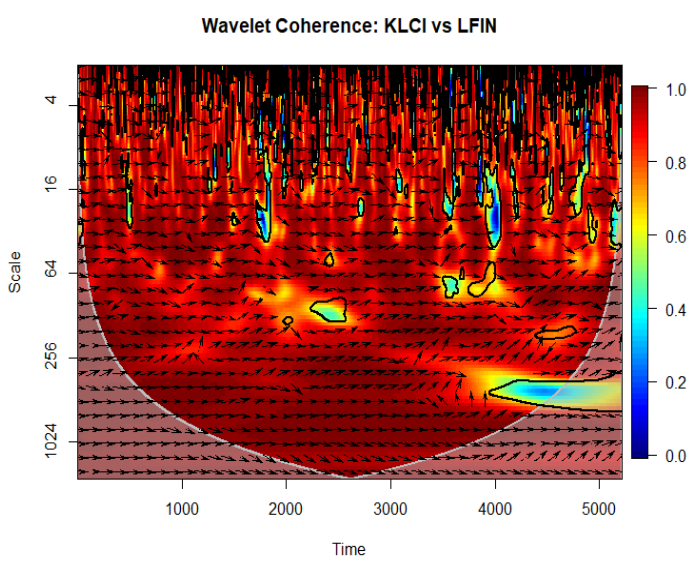

(c) Finance

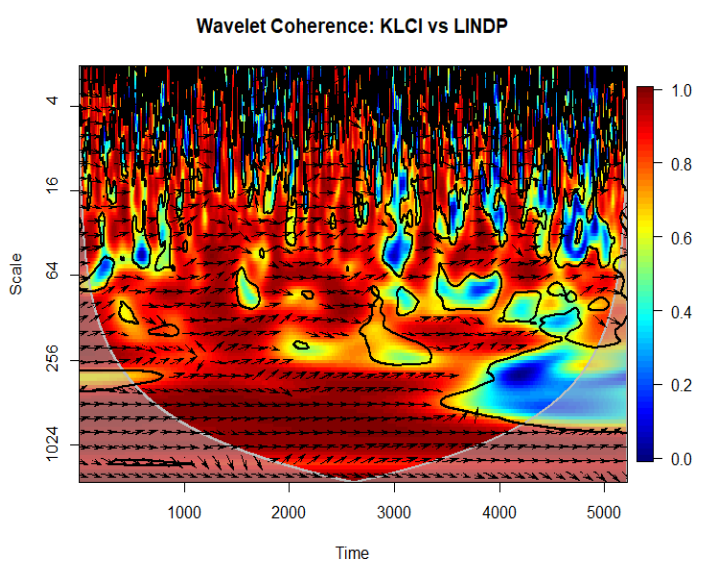

(e) Industrial Product

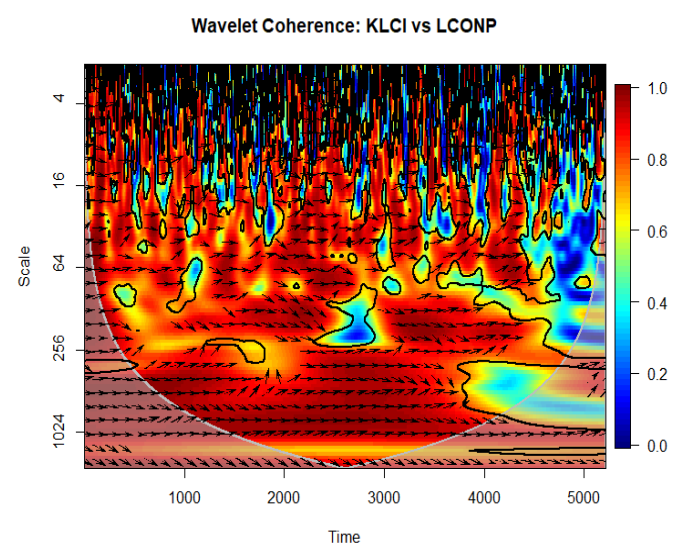

(b) Consumer Product

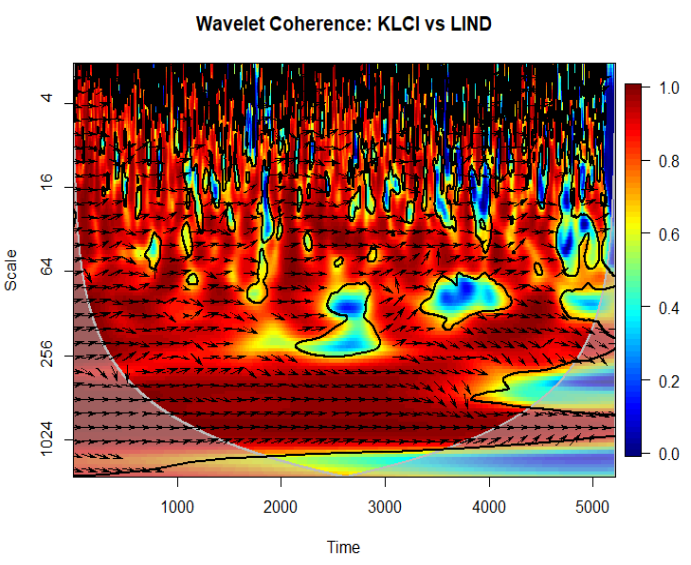

(d) Industrial

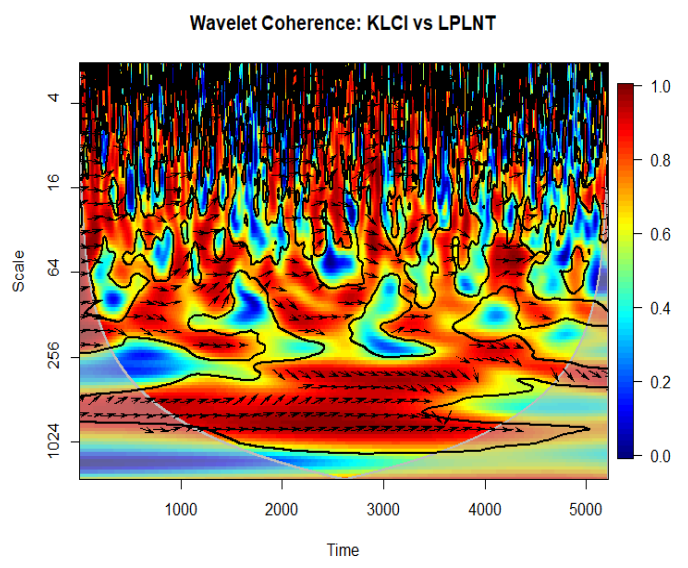

(f) Plantation 


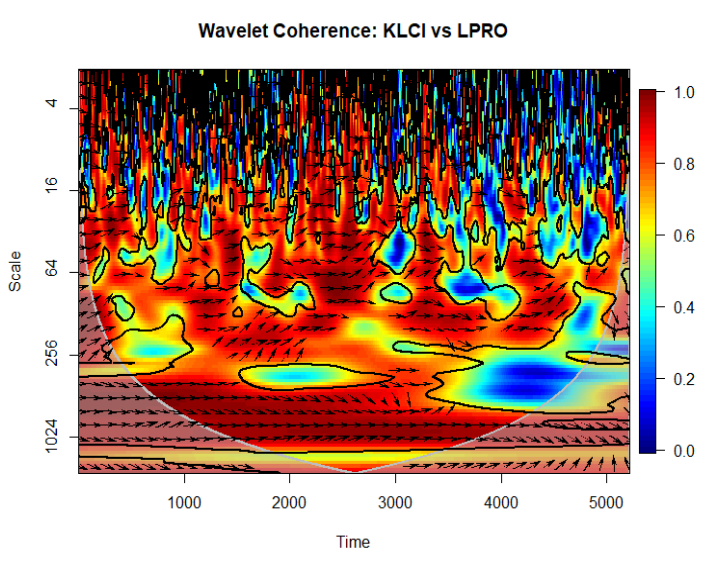

(g) Properties

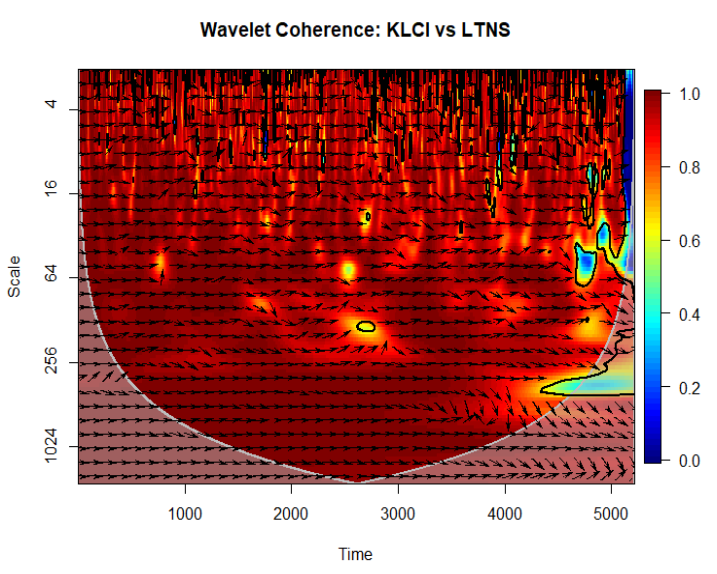

(i) Trade and Services

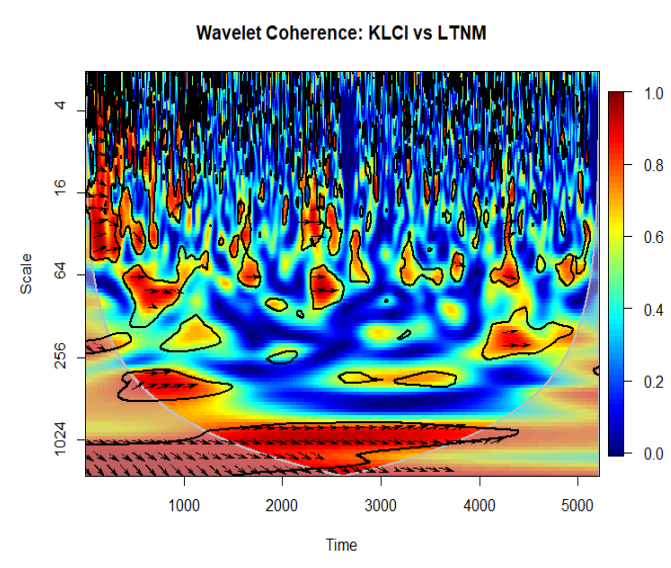

(h) Tin and Mining

\begin{tabular}{|l|l|l|l|l|}
\hline 1000 & 2000 & 3000 & 4000 & 5000 \\
\hline 2003 & 2007 & 2011 & 2015 & 2019 \\
\hline
\end{tabular}

The verticle axis is the frequency component, while the horizontal axis is the time component; The thick black contour represents regions at the $5 \%$ level, and the curved black line denotes a cone of influence, which indicates the regions affected by edge effects. Right up and down show in-phase, while left up and down represent out of phase.

\subsection{The estimated conditional volatilities of equity sector return and composite index}

Figure 2 illustrates the time-varying properties of conditional volatilities of the equity sectors return with the Malaysian composite index. The figure shows that the consumer product sector has the lowest volatility whereas the tin and mining sector has the highest volatility. The equity sectors return and composite index follow the same trend, with composite index moving closely together except in tin and mining sector. The tin and mining sector is affected by the financial crisis while other equity sectors are less affected. The other equity sector could be a better option in terms of portfolio diversification for investors in equity markets because of its low volatility.

\subsection{The estimated conditional correlations of equity sector return and composite index}

Figure 3 presents DCC-GARCH model of Engle (2002) and reveals the conditional correlation of the equity sectors return with the Malaysian composite index. The result highlights that the three sector indexes namely tin and mining, plantation and properties are weakly correlated with the composite index. At the beginning of 2000 , the correlation among these indexes was very low and positive; afterward, it turned negative during 2000, which is a very attractive option for investors in this equity market. By contrast, the tin and mining sector has low correlation with the composite index, but the correlation increased at the beginning of 1999, after which it declined and even became negative at the end of 2018 . 
Meanwhile, other sectors in this figure, the lines move up and down, which indicates that correlations among these indexes vary over time.

\section{Plot of conditional volatilities and correlations}

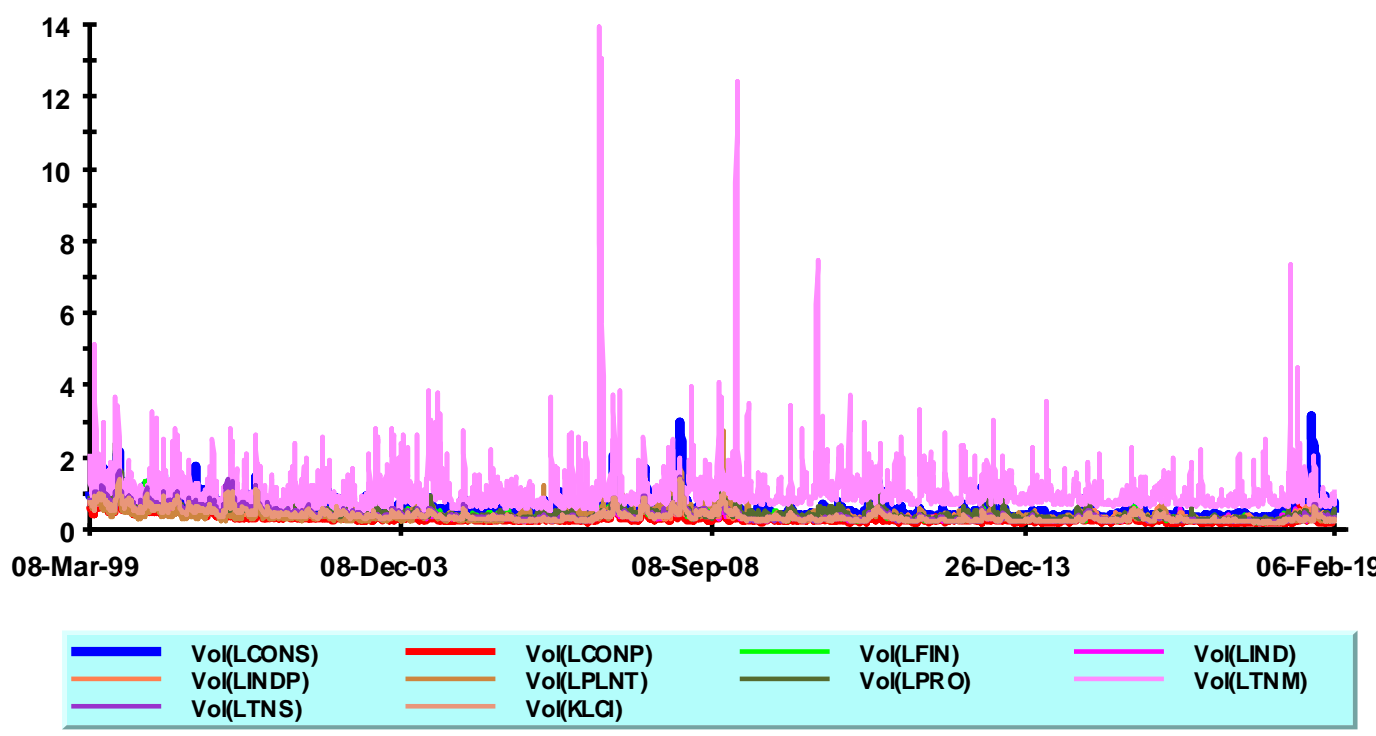

Figure 2. Conditional volatilities of Malaysian equity sector return and composite index

The results reveal that the correlation coefficients are the highest in trade and service sector. They vary between 0.297 for tin and mining sector to 0.947 for trade and services sector. The estimated correlation coefficients for the equity sectors are mostly significant. Since diversification potential is closely related to correlation levels, the evidence of the low cross-sector correlations in equity market suggests that the inclusion of these sectors may help reduce the risk of the portfolio.

\section{Plot of conditional volatilities and correlations}

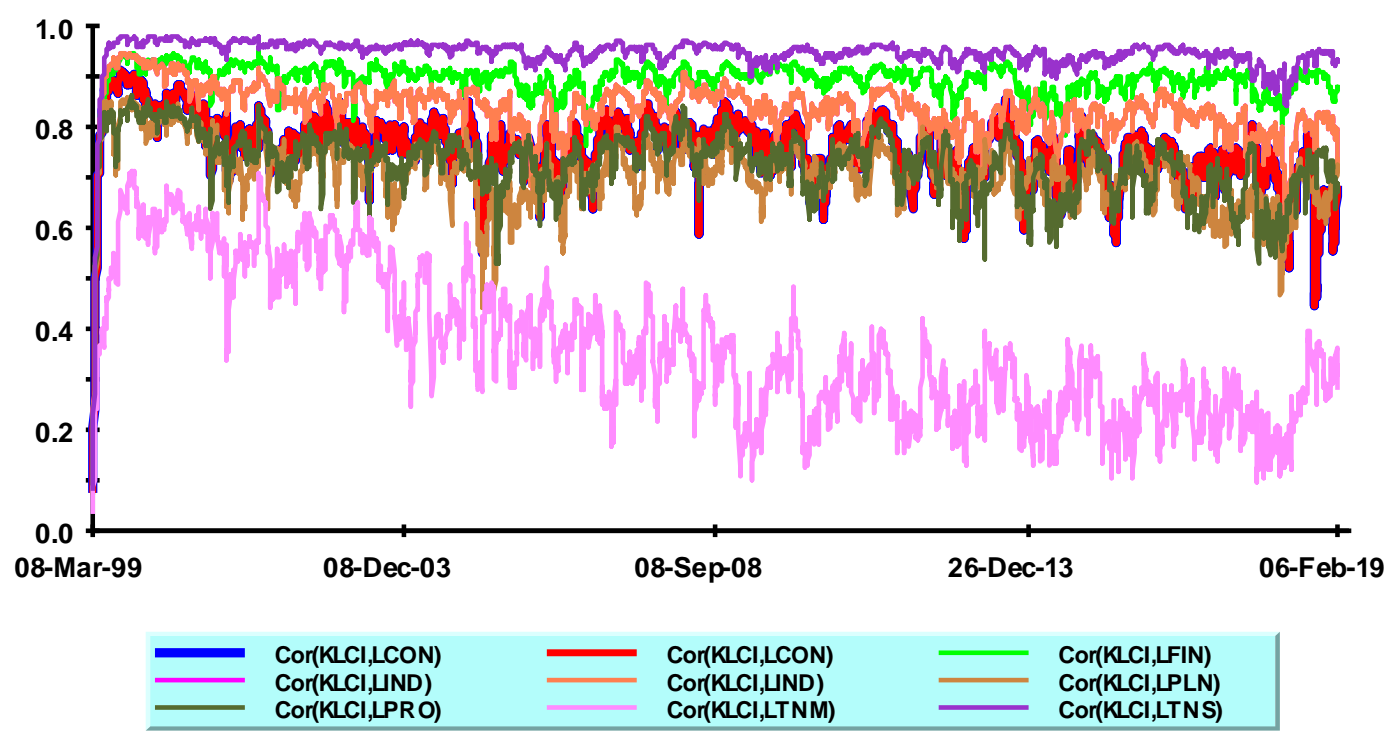

Figure 3. Conditional correlations of Malaysian equity sector return with composite index

\section{Conclusions}

The time-frequency domain analysis conducted in this paper can benefits from the portfolio diversification with the sectoral indices in Malaysia. A discussion on the dynamic relationship of return in 
Malaysian equities among comprehensive sector is rare in the field of finance. This study provides new insight into the co-movement and lead/lag relationship among Malaysian equities sectors from 1999 to 2019. To analyze the issue in detail, this study has distinguished the time-frequency relationship between sector return by using continuous wavelet approach and MGARCH-DCC. The results of the study highlight that wavelet coherence illustrates higher co-movement between equity sector returns with the Malaysian composite index returns during the sample period. The finding reveals that majority of sectors strongly comove. In addition, the impact changes across low-frequency scales. More specially, the sectors are positively associated with each other. In term of long-term investment period, ranging from 256 to 1024 days and medium-term investment horizons ranging from 64 to 256 days, the tin and mining sector offer better diversification benefits for equity investors during sample period.

In terms of conditional correlation, the tin and mining, plantation and properties sectors are suitable for equity investors because of very low correlation. Moreover, the three sectors have negative conditional correlation with the composite index, which is a good sign for gaining diversification benefits for retail and institutional investors. Overall, the correlations of equity sector indexes are vary over time. After analyzing the developed bond market, Poynter et al. (2013) recommends that sectoral diversification benefits can be gained for investors with long-term investment horizons for their equity investments, which is similar to the findings of this study. Further research should examine the co-movement of risk through the co-movement on a sectoral level. Although most of the previous studies have been focusing on the co-movement of country-level market indices, much less is known at sector levels. Therefore, a deeper understanding of risk and return behavior of such equity indices, and, in particular, their determinants, can help sustain the increasing interest of investors in the industry.

\section{References}

1. Aguiar-Conraria, L., Azevedo, N., \& Soares, M. J. (2008). Using wavelets to decompose the timefrequency effects of monetary policy. Physica A: Statistical Mechanics and its Applications, 387(12), 28632878.

2. Albulescu, C., Goyeau, D., and Tiwari, A. (2015). Contagion and Dynamic Correlation of the Main European Stock Index Futures Markets: A Time-frequency Approach. Procedia Economics and Finance, 20, 19-27.

3. Aloui, C., Hammoudeh, S., \& Hamida, H. Ben. (2015). Co-movement between sharia stocks and sukuk in the GCC markets: A time-frequency analysis. Comput Econ, 34, 69-79. https://doi.org/10.1016/j. intfin.2014.11.003

4. Balli, Faruk, \& Balli, Hatice, O. (2011). Sectoral equity returns in the Euro region: Is there any room for reducing portfolio risk? Journal of Economics and Business, 63(2), 89-106.

5. Ben-Salha, O., Hkiri, B., \& Aloui, C. (2018). Sectoral energy consumption by source and output in the U.S.: New evidence from wavelet-based approach. Energy Economics, 72, 75-96. https://doi.org/10.1016/j.eneco.2018.03.029

6. Benlagha, N. (2014). Dependence structure between nominal and index-linked bond returns: A bivariate copula and DCC-GARCH approach. Applied Economics, 46(31), 3849-3860. https://doi.org/10. 1080/00036846.2014.943886

7. Buchanan, B. G., English, P. C., \& Gordon, R. (2011). Emerging market benefits, investability and the rule of law. Emerging Markets Review, 12(1), 47-60. https://doi.org/10.1016/j.ememar.2010.09.001

8. Chen, M. P., Chen, W. Y., \& Tseng, T. C. (2017). Co-movements of returns in the health care sectors from the US, UK, and Germany stock markets: Evidence from the continuous wavelet analyses. International Review of Economics and Finance, 49(July 2015), 484-498. https://doi.org/10.1016/j.iref. 2017.02.009

9. El Alaoui, A. O., Dewandaru, G., Rosly, A. S., \& Masih, M. (2014). Linkages and co-movement between international stock market returns: Case of Dow Jones Islamic Dubai Financial Market index. In Journal of International Financial Markets, Institutions and Money (Vol. 36). https://doi.org/10.1016/j. intfin.2014.12.004 
10.Erdogan, O., Tata, K., Karahasan, B. C., \& Sengoz, M. H. (2013). Dynamics of the co-movement between stock and maritime markets. International Review of Economics and Finance, 25(2), 282-290. https://doi.org/10.1016/j.iref.2012.07.007

11.Graham, M., \& Nikkinen, J. (2011). Co-movement of the finnish and international stock markets: A wavelet analysis. European Journal of Finance, 17(5-6), 409-425. https://doi.org/10.1080/1351847X. 2010.543839

12.Hargis, K., \& Jianping, M. (2006). Is Country Diversification Still Better Than Sector Diversification? European Financial Management, 33(2), 319-340 Is. https://doi.org/10.2469/dig.v33.n2.1279

13.Liow, H. K. (2012). Co-movements and Correlations Across Asian Securitized Real Estate and Stock Markets. Real Estate Economics, 40(1), 97-129. https://doi.org/10.1111/j.1540-6229.2011.00314.x

14.Hillier, D., and Loncan, T. (2019). Stock market integration, cost of equity capital, and corporate investment: Evidence from Brazil. European Financial Management, 25(1), 181-206.

15.Kallberg, J., \& Pasquariello, P. (2008). Time-series and cross-sectional excess comovement in stock indexes. Journal of Empirical Finance, 15(3), 481-502. https://doi.org/10.1016/j.jempfin.2007.06.002

16.Kim, M., \& Sun, L., (2017). Dynamic conditional correlations between Chinese sector returns and the S\&P 500 index: An interpretation based on investment shocks. International Review of Economics \& Finance, 48, 309-325.

17.Liew, P., Lim, K., \& Goh, K. (2018). Foreign equity flows: Boon or bane to the liquidity of Malaysian stock market?. The North American Journal Of Economics And Finance, 45, 161-181. doi: 10.1016/j.najef.2018.02.007

18.Liow, K. H., \& Angela, S. Y. (2017). Return and co-movement of major public real estate markets during global financial crisis: A frequency domain approach. Journal of Property Investment and Finance, 35(5), 489-508. https://doi.org/10.1108/JPIF-01-2017-0002

19. Marfatia, H. A. (2017). A fresh look at integration of risks in the international stock markets: A wavelet approach. Review of Financial Economics, 34(1), 33-49. https://doi.org/10.1016/j.rfe.2017.07.003

20.Mensah, J. O., \& Premaratne, G. (2017). Dependence patterns among Asian banking sector stocks: A copula approach. Research in International Business and Finance, 41(April), 516-546. https://doi.org/10.1016/j.ribaf.2017.05.001

21.Mensi, W., Hammoudeh, S., Al-Jarrah, I. M. W., Sensoy, A., \& Kang, S. H. (2017). Dynamic risk spillovers between gold, oil prices and conventional, sustainability and Islamic equity aggregates and sectors with portfolio implications. Energy Economics, 67, 454-475. https://doi.org/10.1016/j.eneco. 2017.08.031

22.Mensi, W., Hammoudeh, S., \& Kang, S. H. (2017). Risk spillovers and portfolio management between developed and BRICS stock markets. North American Journal of Economics and Finance, 41, 133155. https://doi.org/10.1016/j.najef.2017.03.006

23.Mimouni, K., Charfeddine, L., \& Al-Azzam, M. (2016). Do oil producing countries offer international diversification benefits? Evidence from GCC countries. Economic Modelling, 57, 263-280. https://doi.org/10.1016/j.econmod.2016.05.001

24.Dahir, M. A., Mahat, F., Ab Razak, N. H., \& Bany-Ariffin, A. N. (2018). Revisiting the dynamic relationship between exchange rates and stock prices in BRICS countries: A wavelet analysis. Borsa Istanbul Review, 18(2), 101-113. https://doi.org/10.1016/j.bir.2017.10.001

25.Poynter, J. G., Winder, J. P., \& Tai, T. (2013). An analysis of co-movements in industrial sector indices over the last 30 years. Review of Quantitative Finance and Accounting, 44(1), 69-88. https://doi.org/10.1007/s11156-013-0399-z

26.Reboredo, J. C., \& Uddin, G. S. (2016). Do financial stress and policy uncertainty have an impact on the energy and metals markets? A quantile regression approach. International Review of Economics and Finance, 43, 284-298. https://doi.org/10.1016/j.iref.2015.10.043

27.Rehman, M. U., \& Shah, S. M. A. (2016). Determinants of Return's Co-Movement for Effective Portfolio Diversification Among Regional Stock Markets. Revista Evidenciação Contábil \& Finanças, 4(1), 8496. https://doi.org/10.18405/recfin20160106

28.Sakemoto, R. (2018). Co-movement between equity and bond markets. International Review of Economics and Finance, 53(October 2017), 25-38. https://doi.org/10.1016/j.iref.2017.10.013 
29.Shahzad, S. J. H., Ferrer, R., Hammoudeh, S., \& Jammazi, R. (2018). Industry-level determinants of the linkage between credit and stock markets. Applied Economics, 50(49), 5277-5301. https://doi.org/10.1080/00036846.2018.1486986

30.Shahzad, S. J. H., Nor, S. M., Sanusi, N. A., \& Kumar, R. R. (2017). The lead-lag relationship between US industry-level credit and stock markets. Journal of Economic Studies, 44(4), 518-539. https://doi.org/10.1108/JES-03-2016-0053

31.Shahzad, S., Nor, S., Kumar, R., \& Mensi, W. (2017). Interdependence and contagion among industry-level US credit markets: An application of wavelet and VMD based copula approaches. Physica A: Statistical Mechanics And Its Applications, 466, 310-324. doi: 10.1016/j.physa.2016.09.008

32.Sharif, A., Jammazi, R., Raza, S., \& Shahzad, S. (2017). Electricity and growth nexus dynamics in Singapore: Fresh insights based on wavelet approach. Energy Policy, 110, 686-692. doi: 10.1016/j.enpol. 2017.07.029

33.Torrence, C., \& Compo, G. (1998). A Practical Guide to Wavelet Analysis. Bulletin Of The American Meteorological Society, 79(1), 61-78. doi: 10.1175/1520-0477(1998)079<0061:apgtwa>2.0.c0;2

34.Vacha, L., \& Barunik, J. (2012). Co-movement of energy commodities revisited: Evidence from wavelet coherence analysis. Energy Economics, 34(1), 241-247. https://doi.org/10.1016/ j.eneco.2011.10.007

35.Yang, L., Cai, X., Zhang, H., \& Hamori, S. (2016). Interdependence of foreign exchange markets: A wavelet coherence analysis. Economic Modelling, 55, 6-14. doi: 10.1016/j.econmod.2016.01.022

36.Zaremba, A., \& Maydybura, A. (2019). The cross-section of returns in frontier equity markets: Integrated or segmented pricing?. Emerging Markets Review, 38, 219-238. doi: 10.1016/j.ememar. 2019.02.003 